\title{
REPRESENTING THE VALUE PROPOSITION OF PRODUCT- SERVICE SYSTEMS (PSS) IN A VALUE-BASED PERSPECTIVE
}

\author{
Fernandes, Sânia da Costa; Martins, Luiza Diegues; Campese, Carina; Rozenfeld, Henrique \\ University of São Paulo
}

\begin{abstract}
Product-service systems (PSS) are being increasingly employed as opportunities to keep innovating. The design of PSS value propositions should focus on the value visualization for stakeholders. However, the PSS representations are still oriented to the customer' perspective and focus on a process or technological role. This study aims to represent the PSS value proposition in a structured-diagram adapted from the journey map method in combination with the use of the elements of value. A case research was conducted with a high-tech agricultural start-up for representing its value proposition by following a process founded in the practices of journey mapping. Qualitative data analysis was employed to associate the elements of value with the solution, and to verify the consistency of the results. The representation enables the visualization of the stakeholders' perception regarding the content of the solution as well as the potential value that may be related to it. The experience-centric perspective derived from the journey map associated with the value-related information provides a richer view of the PSS value proposition, which can lead to reflections regarding the solution.
\end{abstract}

Keywords: Product-Service Systems (PSS), Design practice, Case study

\section{Contact:}

Fernandes, Sânia da Costa

University of São Paulo

Production Engineering

Brazil

saniafernandes@usp.br

Cite this article: Fernandes, S.S., Martins, L.D., Campese, C., Rozenfeld, H. (2019) 'Representing the Value Proposition of Product-Service Systems (PSS) in a Value-Based Perspective', in Proceedings of the 22nd International Conference on Engineering Design (ICED19), Delft, The Netherlands, 5-8 August 2019. DOI:10.1017/dsi.2019.316 


\section{INTRODUCTION}

The complexity level in Product-Service System (PSS) design raises due to the integrated development of products and services since the early stages of the design process (Bertoni, Bertoni and Isaksson, 2013). PSS combines a collection of tangible and intangible elements organized around interactions for generating value (Goedkoop et al., 1999; Cavalieri and Pezzotta, 2012).

PSS value propositions combine products and services and denote the value that the company may provide for customers and other stakeholders (Resta et al., 2017). Value results from the trade-off between benefits and sacrifices (Bertoni, Rondini and Pezzotta, 2017). Although value is co-created based on subjective and experiential perceptions, the PSS provider can determine, even qualitatively, the potential benefits that can be offered to stakeholders through the value proposition (Grönroos and Voima, 2013). On the one hand, it relies on the value proposition attributes (Tan, 2010). On the other hand, the benefits are determined by companies through interactions with customers and other stakeholders to become aware of their expectations and practices employed to set experiences and perceptions in a specific context. It means that the provider generates potential benefits that can be turned into real value in use situations (Grönroos and Voima, 2013).

Visualizing, in the early stages of design, the PSS value proposition through the lens of the potential benefits considering the stakeholders' perspective is challenging. During the design, the company aims to achieve the expectations of all relevant stakeholders throughout the system's lifecycle by considering the benefits under the conceptualization of a combination of products and services. Universal building blocks of value, called by Almquist, Senior and Bloch (2016) as "elements of value", create opportunities for identifying which benefits might be perceived from value propositions according to the interests and concerns of stakeholders.

Although a plethora of methods have been developed to represent the PSS (Morelli and Tollestrup, 2007; Lim et al., 2012), most of them are focused on depicting product features, organizational process of services against the customer actions, and the relational network of PSS stakeholders (Lim et al., 2012). The literature is scarce in foresing and visualizing the possible future experiences of stakeholders given a PSS solution. In some representations, the potential benefits of the solutions are extracted based on the requirements of stakeholders rather than being determined according to their perceptions, which are derived from the experiences. Representing the potential value proposition (i.e., the integrated solution and its potential benefits based on the stakeholders' perspective) can be useful for design teams and it can be used as a low-fidelity prototype for the decision-making during the design process.

Given the aforementioned gaps, this study aims to represent the PSS value proposition of a real case by depicting the possible future experience of stakeholders in association with the use of the elements of value. The elements of value act as the potential benefits and they were associated with each idea aggregated into the value proposition. We highlight that the description of the process employed to design the value proposition and the quantitative value assessment are out of the scope of this study.

This paper is structured as follows. Section 2 presents a description of methods for representing some perspectives of PSS value proposition and the explanation about the elements of value. Section 3 presents the research methodology. The main findings and discussions are presented in section 4 . The paper ends with section 5, which presents the conclusion and further research opportunities.

\section{BACKGROUND}

\subsection{Methods for representing the PSS value proposition}

PSS value proposition representation involves the use of a structured-diagram to show the PSS elements and their relationships (Yip, Phaal and Probert, 2015).

Service Blueprint (Shostack, 1982) is among the most discussed methods for representing the PSS process. This method depicts the organizational process of services and interactions between the company and customers, showing the support processes as well as visible or invisible processes to customers. In order to capture the specific characteristics of PSS, variants of service blueprint have been developed. One of them is the Product-Service Blueprint (Geum and Park, 2011), which supports the visualization of PSS process in product-related, service-related, and supporting-related areas. The system map is one of the methods employed to represent the relationship between stakeholders and other elements of the system. It depicts the entities as well as the flow of materials, information, and money through the system (Morelli and Tollestrup, 2007). Other approaches include the PSS Board, which is 
based on a matrix board for representing the components of the PSS and the customer activities, the general steps of PSS process, and specific processes of companies and customers (Lim et al., 2012). The Functional Block Diagram is used to model the PSS structure, combining the representation of the physical object, the service unit and the outer environment (Maussang, Zwolinski and Brissaud, 2009).

Expanding the traditional representations of PSS value proposition toward the visualization of valuerelated information, Kim et al. (2009) proposed a graphical and ontological representation of the relationships among products, services, stakeholders, and value of PSS. The Lifecycle Value Representation is another approach developed to represent the value of product concepts to design teams in the preliminary stages of PSS design (Bertoni, Bertoni and Isaksson, 2013). In the PSS characterization approach, Yip, Phaal and Probert (2015) proposed to identify the level of perceived value by customers regarding a PSS offering.

However, those methods do not represent the value proposition combined with the potential benefits from the perceptions of stakeholders. Those methods focused on depicting information related to PSS process, the stakeholders' network, the technical elements organized in system architecture, specific functionalities of the system, etc. (Morelli and Tollestrup, 2007; Lim et al., 2012).

\subsection{Elements of value}

Value is a multi-perspective construct which integrates different aspects beyond the limits of organizations (Gilles and Christine, 2016). Using value models, Panarotto (2015) argues that value clarifies the design trade-offs between benefits and sacrifices for selecting the most valuable alternative among a set of possible ones. Benefits are related to positive motivations when fulfilling the needs (Sampson, 2012). In turn, sacrifices are what one gives up when acquiring a product/service or learning how to use it. Sacrifices include price, time, and effort (Roy and Cheruvu, 2009).

Almquist, Senior and Bloch (2016) identified thirty elements of value that may be related to the value propositions in the market. The elements of value are divided into four categories. The following definitions were proposed for each category (Fernandes, Rosa and Rozenfeld, 2017):

- Functional: it is related to the basic values for stakeholders, being associated with practical purposes that effectively reflect in some function in their day to day;

- Emotional: values associated with the generation of positive emotions for stakeholders;

- Change of life: refers to values that are associated with the capacity to change or influence the perspective on which the stakeholders analyze the world;

- Social impact: values related to the search for the common good, focusing on the improvement of the living conditions of people with whom the stakeholders have empathy.

The elements of value are shown in Figure 1. According to Almquist, Senior and Bloch (2016), value propositions with a greater number of elements of value are more likely to be accepted in the market.

\section{RESEARCH METHODOLOGY}

Participatory case research (Yin, 2003) was conducted with a high-tech agricultural start-up. The startup, called HeliDrop ${ }^{1}$, intends to offer pulverization services using drones, being responsible for drone development and operation. The question explored through the case research was "How could the PSS value proposition of HeliDrop be represented in a structured-diagram combining the possible future experiences of stakeholders and the elements of value?".

In order to answer the research question, a structured template (Figure 2) was elaborated. The first layer refers to the PSS value proposition described in a process perspective. The second layer depicts the possible future experiences of the stakeholders, which are plotted throughout the content of the value proposition, signaling the "ups" and "downs" related to those possible future experiences of the stakeholders given a solution. The third layer shows which elements of value (i.e., potential benefits) can be perceived by the stakeholder in relation to each part of the value proposition.

1 For more information about the start-up, please access http://www.helidrop.com.br 


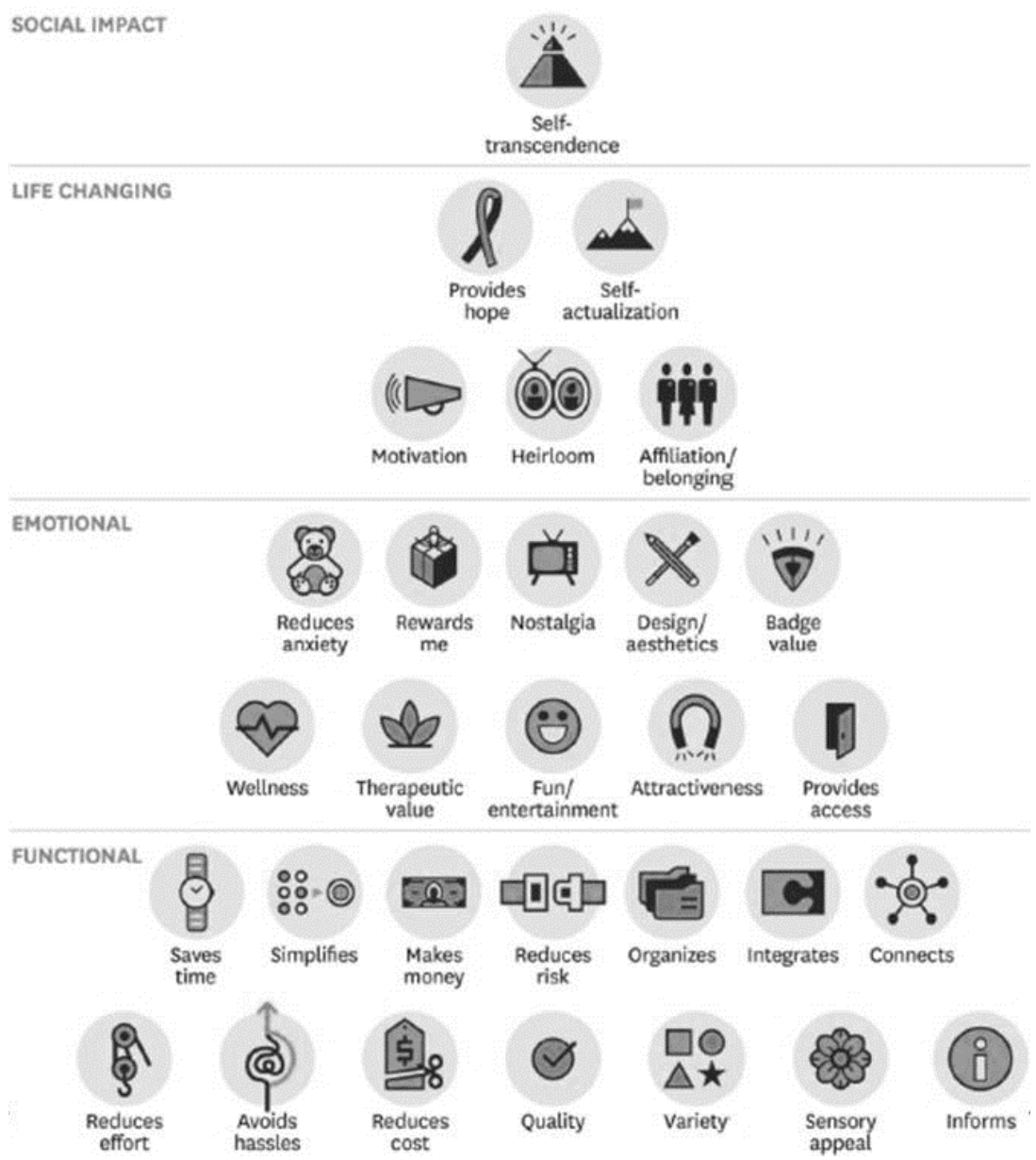

Figure 1. Elements of value Adapted from Almquist, Senior and Bloch $(2016$, p. 3)

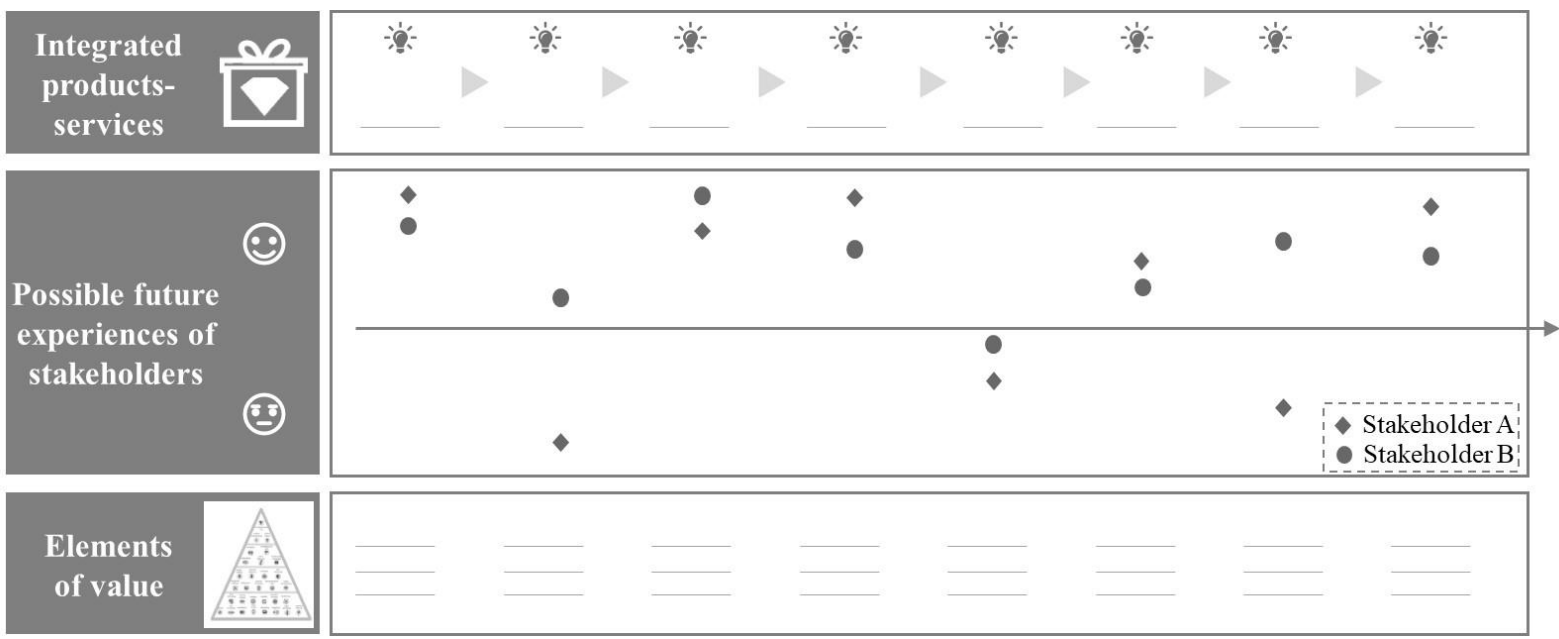

Figure 2. Structured-diagram for representing the potential PSS value propositions Elaborated by the authors

The value proposition of HeliDrop, which is described in the first layer of the structured-diagram, was designed by applying the PSS design and servitization methodology ${ }^{2}$ (Rozenfeld, Rosa and Fernandes, 2018). Farmers were selected as the most important stakeholder group to HeliDrop. Because of this, in this study, their possible future experiences were mapped regarding the value proposition (in the second layer of the structured-diagram). The journey map was used as inspiration to define how to map the

2 For more details regarding the activities and methods employed to design the value proposition, please refer to the official documentation (Rozenfeld, Rosa and Fernandes, 2018) (for more information, access http://www.pdp.org.br/servmtd/). 
experiences of the stakeholder. This method can be used for translating the experience of customers when interacting with a product or service (Sperano et al., 2019). It could also be used to improve those experiences and reach new insights into the journey (Følstad and Kvale, 2018). Usually, five steps can be followed to map the journey: consolidate information that the company already have about the customers, develop initial hypotheses about the customer, identify customer's processes and perceptions, analyze data gathered about the customer, and map the customer journey (Temkin, 2010). To gather information about the customer, two means can be used: interviews (for qualitative purposes) or surveys (for quantitative purposes) (Nenonen, Rasila and Junnonen, 2008). Although the use of the journey map is still focused on understanding the customer experience instead of considering other stakeholders' experiences (Ortbal, Frazzette and Mehta, 2016), this method is used as reference in this proposal since it allows the plotting of positive and negative experiences of the individuals (Sperano et al., 2019) which can be translated into the elements of value.

The steps proposed by Liedtka and Ogilvie (2011) were adapted to map the possible future experiences of the farms. The mapping was performed through the process of:

- Selecting the stakeholder group whose perception of the value proposition would be understood;

- Identifying individuals that fitted into the stakeholder group;

- Conducting interviews with those individuals to verify the consistency of the value proposition. For this, the value proposition was presented and explained in detail to the stakeholder;

- Identifying the "ups" and "downs" for each individual based on the interview results. The "ups" and "downs" reflect on the possible future experiences that have been expressed by the stakeholder regarding each part of the value proposition;

- $\quad$ Searching for patterns, through qualitative analysis (Elo and Kyngäs, 2008), about the perception of the stakeholder group considering the interpretation of data gathered through the interviews;

- Mapping the possible future experience. Instead of using a quantitative scale, the experiences were mapped in a qualitative way based on the feedback from interviewees.

Five farmers were interviewed. They were inquired about the understanding of the content of the value proposition and whether it addresses their problems, needs, and opportunities. They were also inquired about their perception of resulting benefits regarding each part of the value proposition and the possible future experiences. During this process, the owners of the start-up acted as conductors of the interviews in order to maximize information capturing. They also made use of distinct data sources when possible, such as direct observation and informal conversations. The participation of the owners of the start-up was essential for processing the information when dealing with technical aspects of the value proposition and the jargon used by the interviewees.

Afterward, the elements of value were associated with each part of the value proposition (third layer) through qualitative data analysis (Elo and Kyngäs, 2008) based on the results of the interviews with the farmers. The elements of value were treated as the potential benefits that may be provided by the PSS. Finally, the consistency of the results was verified by an expert in PSS design regarding the understanding of the representation and the association of the elements of value. The expert also analyzed the alignment of the process for representing the value proposition within the PSS design.

\section{RESULTS}

\subsection{PSS value proposition representation}

The start-up HeliDrop is developing a spraying drone by means of which pest control service will be offered to Brazilian sugarcane producers. The PSS will be based on payment per service unit (Tukker, 2004). According to the Brazilian Sugarcane Industry Association (UNICA, 2018), Brazil is one of the sugarcane producer leaders in the world market. The national production is concentrated in the Southeast region (UNICA, 2018), at where HeliDrop intends to settle on. The sugarcane industry is open to innovative offerings that could contribute to the competitiveness challenge.

Customized solutions are required in this sector. Traditional sprayers (e.g., tractor and airplane) do not have high load capacity, whose aspect leads to low flying autonomy and high time processing. It also intensifies logistic problems related to transportation and refueling. In general, the main needs and opportunities for the sugarcane field reveal to be: a spraying solution with the ability to cover varied terrains, being approachable to all size farmers at the same time that enables the pulverization of 
specific areas; precise mapping of the spraying route; control of the sprayed area and provision of detailed reports; cost-effectiveness.

The identification of that information and the design of the PSS value proposition of HeliDrop was done by applying the PSS design and servitization methodology (Rozenfeld, Rosa and Fernandes, 2018). In a high-level description, the value proposition of HeliDrop consists of spraying with an autonomous drone for the application of pesticides over a wider spraying span, being convenient to carry and work continuously, and able to provide the most relevant information about the spraying process. A more detailed description of HeliDrop's products and services integrated into the solution, which was consolidated after the ideation process (Rozenfeld, Rosa and Fernandes, 2018), is shown in Figure 3 and further explained.

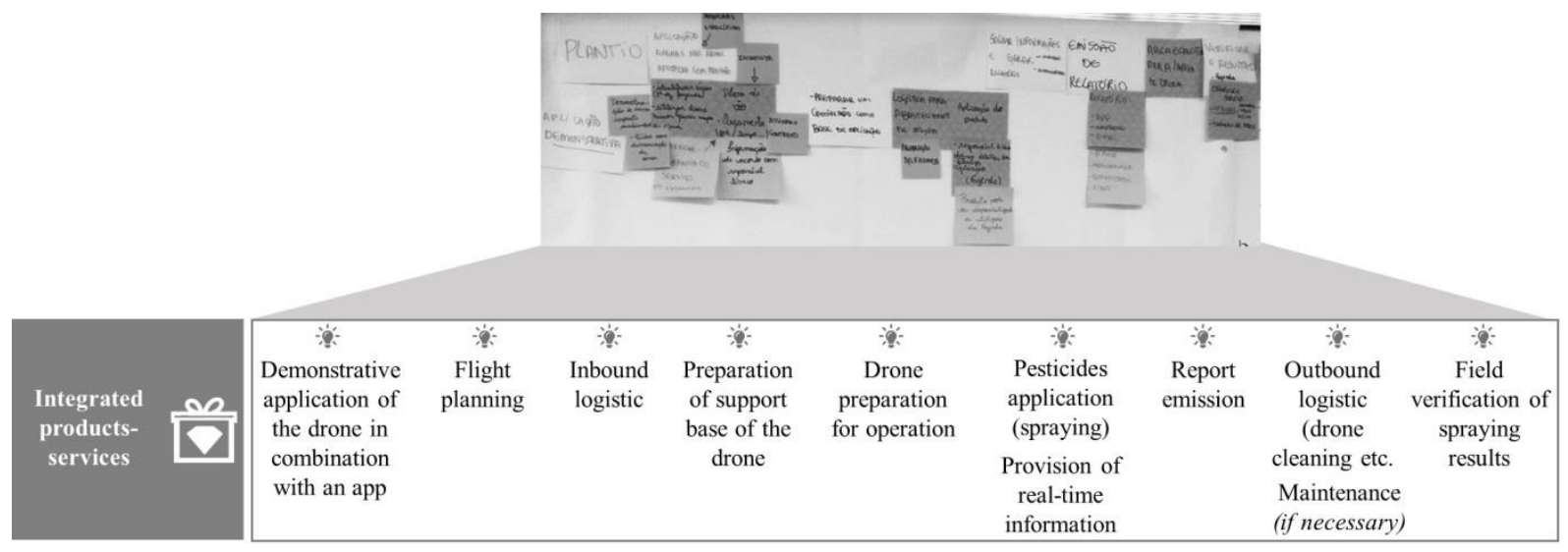

Figure 3. Integrated products and services related to HeliDrop's value proposition Elaborated by the authors

First, the start-up will provide farmers a demonstrative application of the spraying process using the drone. The aim is to show the spraying process of liquid pesticides on agricultural land and to present an overview of the main features of the drone as well as the advantages that can be achieved compared to traditional sprayers. Based on a simulation, it is possible to demonstrate the wide range of application regarding the terrain, altitudes flights, size of the pesticides' drop, environment protection issues, water saving, and so on. At the same time, through the demonstrative application, the start-up can analyze the terrain characteristics, which favors the definition of customized applications.

The flight planning consists in recognizing the terrain and crop conditions, and in scheduling the flight by mapping specific target areas to be sprayed. Technical information of the drone will be settled up.

The start-up will provide the infrastructure and perform the activities for preparing the drone for operation. This includes the decisions related to transporting the drone to the farm, locating, and preparing the drone base, setting-up the drone for operation, water supply, fuel supply, and so on. Subsequently, the spraying process will be performed, being monitored by an agronomist. Real-time information will be provided to farmers and agronomists while spraying is performed. Detailed reports will also be provided through an app at where all information related to the spraying process can be consolidated (e.g., target areas, amount of pesticides applied, weather data, etc.).

Once the spraying process is finished, the outbound logistics will be carried out. This includes the drone clean up and the preparation of the infrastructure's removal from the farm. Corrective maintenance (in cases where it is not necessary to interrupt the operation of the drone), or even the preventive maintenance will be carried out as the outbound logistic is carried out. Finally, the results from the spraying process will be certified by the farmer and agronomists. If it is identified that a target area has not been sprayed, the start-up should be contacted and comply with the service level agreement.

The potential value proposition of HeliDrop is represented in Figure 4. The owners of the start-up and the authors were responsible for representing the value proposition based on data gathered from the interviews with the farmers. 


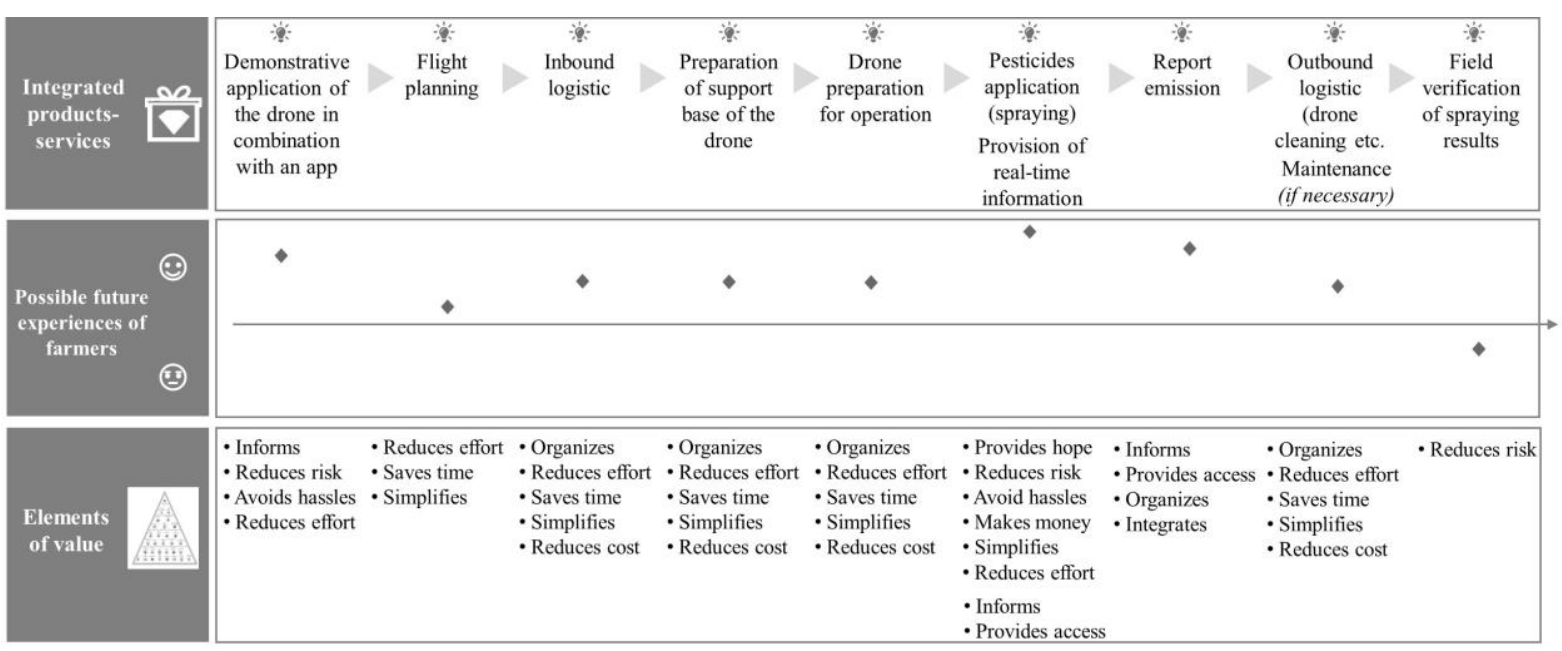

Figure 4. Representation of the potential value proposition of HeliDrop Elaborated by the authors

The demonstrative application of the spraying drone can imply in positive experiences for farmers. Through it, farmers can be informed about the technical or managerial details of the solution and how the drone will be offered as a service. From the perspective of farmers, the risk of contracting a lowquality service can be reduced as farmers have the opportunity to evaluate some characteristics of the solution prior to contracting it. As consequence, hassles of farmers can be reduced or avoided. Also, the effort of looking for a company to provide the spraying service can be reduced, since the start-up will have the initiative of contacting promise consumers to offer its PSS value proposition.

As the flight planning will be performed by HeliDrop, farmers will only be responsible for providing input information needed for scheduling the flight and settling up the drone. Thus, efforts can be reduced for farmers. At the same time, their operational activities can be simplified, which also saves time.

The inbound logistic, the preparation of the base of the drone, and the preparation of the drone for operation will be also performed by HeliDrop. This allows the organization of artifacts and physical space on the farm, simplifying the activities for farmers, reducing their efforts, and saving time. Since farmers will not need to purchase artifacts to spray the crop, costs can be avoided or reduced.

The application of pesticides provides hope for farmers. For them, the spraying is a means to avoid loss of plantation. This also implies reducing risks and hassles for farmers while dealing with the business. In a transaction context, the crop is a source for generating revenues for farmers. As HeliDrop will be responsible for spraying the areas, the activities carried out by farmers can be simplified and, consequently, their effort can be reduced.

By means of real-time information and detailed reports, farmers can be informed about the results of the spraying process, whose access to data can be used to improve the planting parameters. Data can be integrated with additional information through online interfaces. Providing reports through an app can make ease of the data organization. Moreover, through real-time information and reports, farmers' hassles can be reduced since they will know that the results can be consulted during and at the end of the spraying process.

The outbound logistics will be carried out by the start-up, and this can imply positive emotions for farmers by reducing their efforts and saving time. Also, farmers will not be responsible for contracting maintenance service for the assets, which simplifies their activities, saves time and avoids costs.

According to the value proposition of HeliDrop, the verification of the results from the spraying process will not be performed by the start-up. Because of this, emotional "down" can be perceived since farmers will be responsible for checking if there is any inconsistency in the crop after the spraying process. Although that activity will not be simplified for farmers, loss risks can be reduced since the detected inconsistencies will be reported to the start-up, which should comply with the service level agreement.

\subsection{Analysis of the PSS value proposition representation}

The representation of the value proposition provides a means for illustrating its content and for communicating the latent perception of stakeholders regarding the ideas aggregated into it. For example, for the first idea in the value proposition (demonstrative application of the drone) it is 
possible to visualize that the possible future experience of the farmer could be high and this could provide four potential benefits (i.e., elements of value: inform, reduces risk, avoids hassles, and reduce efforts). This brought an integrated perspective for the design team. While allowing a greater people's understanding of the system yet under design, the proposed representation allows capturing the emotional state of the stakeholder group. By foreseeing positive and negative experiences of stakeholders, the pain-points and opportunities-points of PSS value proposition may be identified. Those points may indicate which ideas incorporated into the value proposition should be improved or explored.

Associating the elements of value provides visualization of the value-related information, i.e., an overview of the potential benefits that can be perceived from the value proposition considering the perspective of the stakeholders. The elements of value can be seen as a means for summarizing, essentially, the final benefits that may be related to the solution. Combined with the mapping of the possible future experiences, the use of the elements of value also follows an experience-centric approach.

By using the structured-diagram proposed in this study, it is possible to capture several aspects related to the representation of the PSS value proposition, such as the flow of the value proposition regarding the sequence of ideas embedded in it, the understanding of possible future experiences for stakeholders to guide decision-making during the design process, and the potential benefits that can be provided through the solution. By displaying the value proposition in its attributes, the structureddiagram facilitates the achievement of a joint comprehension of the solution and the establishment of new insights for it.

Based on the case research, the part of the value proposition that provides the highest emotional experience for the stakeholder group contains the highest number of elements of value. Although the functional values are the most frequent into the value proposition, potentials for incorporating emotional, life-change and social impact values are claimed to higher. In this sense, the representation of the PSS value proposition enables new insights throughout the design considering the start-up strategy and the stakeholder perspectives.

Framing the value proposition by a team leads to the creation of a shared representation of the solution and how it can contribute to the stakeholder experience. The involvement of stakeholder ensures the development of a big picture of the value proposition in a collaborative way towards an innovation that meets their needs and problems. In the proposed approach, the interviews were carried out with different purposes: to explain the value proposition, to validate its consistency, and to gather data about the potential emotional "ups" and "downs" related to value proposition under the perspective of stakeholders. However, the interpretation of the stakeholder' perceptions was subject to the judgment of the interviewer. It is, therefore, necessary to consider opinions of a great number of stakeholders, since they may have different perceptions regarding the same event.

The interviewees stated the importance of elucidating the content as well as their expectations for the upcoming solution. This kind of representation with the elements of value was relevant to show the potential benefits that farmers could perceive from the PSS value proposition of HeliDrop. According to the expert in PSS design, the representation of the PSS value proposition journey is suitable to depict time-related information of ideas embedded into the value proposition and to show the impact on the stakeholder experience. At the same time, it allows the designer to translate the value proposition into the design process. This may facilitate decision-making. Based on the analysis of the expert, the identification of the elements of value in the early design phases can be a means to communicate in advance the potential benefits of the solution to stakeholders. However, even with the elements of value, the experiences could be better detailed on the map by named or explained in a legend.

\section{CONCLUSION}

This study provides a way to represent the PSS value proposition by depicting the possible future experience of stakeholders in association with the use of the elements of value. It is a new format to reveal the value proposition structure within the design process. In order to achieve the results, one case research was performed with a high-tech agricultural start-up. The proposal contributes to theory by recognizing the importance of visualizing the PSS value proposition beyond its technical scope. It attempts to clarify the value-related information for stakeholders since the early stages of design. This 
study also presents how the journey map can be adapted to represent the PSS value proposition while incorporating the elements of value. Regarding the practical perspective, the proposal can aid practitioners in building awareness of the value proposition in order to derive the activities in the design process. The representation can be used as a means to communicate the potential benefits of solutions to stakeholders.

The structured-diagram can be used as a prototype by the design team in order to validate the value proposition and to guide the decision-making process in the design process. This can enable new insights into the value proposition regarding what should be explored (related to positive experiences) and what should be improved (related to negative experiences). The experiential component derived combined with the use of elements of value provided a richer view of the PSS value proposition.

The case attests the feasibility of adapting the journey map and of using the elements of value in the context of PSS value proposition design. The process of adapting the journey map in this context reveals suitable. The steps employed for building the representation helped in structuring the content of the value proposition and translating the potential perceptions of the stakeholder group. However, in order to better describe the emotional states of stakeholders, the experiences could be named and an assessment scale could be inserted.

Even though this study follows a multiple stakeholder approach, the PSS value proposition journey in the case research was depicted considering the farmer perspective, that is the main customer of the start-up. Points of view of other stakeholders were not considered in that representation. Besides, when considering other focus of analysis of the value proposition, e.g., from the circular economy point of view, some adaptations in the structured-diagram may be required. Consequently, the process of how to represent the PSS value proposition may vary.

Further research shall represent the PSS value proposition considering the perspectives of different stakeholders, showing the trade-offs between their possible future experiences regarding the solution. A quantitative assessment scale can be developed and employed to measure the experiences of stakeholders. New adaptations of the journey map can be performed to complement the representation of the PSS value proposition considering a risk management approach and the circular economy approach.

\section{REFERENCES}

Almquist, E., Senior, J. and Bloch, N. (2016), “The elements of value”, Harvard Business Review, No. September, pp. 46-53.

Bertoni, A., Bertoni, M. and Isaksson, O. (2013), "Value visualization in Product Service Systems preliminary design", Journal of Cleaner Production. Elsevier Ltd, Vol. 53, pp. 103-117. https://dx.doi/org/10.1016/j.jclepro.2013.04.012.

Bertoni, M., Rondini, A. and Pezzotta, G. (2017), "A systematic review of value metrics for PSS design", Procedia CIRP. The Author(s), Vol. 64 No. June, pp. 289-294. https://dx.doi/org/10.1016/j.procir.2017.03.057.

Cavalieri, S. and Pezzotta, G. (2012), "Product-service systems engineering: State of the art and research challenges", Computers in Industry. Elsevier B.V., Vol. 63 No. 4, pp. 278-288. https://dx.doi/org/10.1016/j.compind.2012.02.006.

Elo, S. and Kyngäs, H. (2008), "The qualitative content analysis process", Journal of Advanced Nursing, Vol. 62 No. 1, pp. 107-115. https://dx.doi/org/10.1111/j.1365-2648.2007.04569.x.

Fernandes, S., Da C., Rosa, M., and Rozenfeld, H. (2017), "Uso de elementos de valor para apoiar a definição de conceitos de pss", In: 11 Congresso Brasileiro de Inovação e Gestão de Desenvolvimento de produto. Blucher Design Proceedings, São Paulo, pp. 1-10.

Følstad, A. and Kvale, K. (2018), "Customer journeys: a systematic literature review”, Journal of Service Theory and Practice, Vol. 28 No. 2, pp. 196-227. https://dx.doi/org/10.1108/JSTP-11-2014-0261.

Geum, Y. and Park, Y. (2011), "Designing the sustainable product-service integration: A product-service blueprint approach", Journal of Cleaner Production, Vol. 19 No. 14, pp. 1601-1614. https://dx.doi/org/10.1016/j.jclepro.2011.05.017.

Gilles, N. and Christine, L. C. (2016), "The Sustainable Value Proposition of PSSs: The Case of ECOBEL 'shower Head"', Procedia CIRP. Elsevier B.V., Vol. 47, pp. 12-17. https://dx.doi/org/10.1016/j.procir.2016.03.043.

Goedkoop, M. J. et al. (1999), "Product Service systems, Ecological and Economic Basics", Economic Affairs. The Netherlands. https://dx.doi/org/10.1111/j.1365-294X.2004.02125.x. 
Grönroos, C. and Voima, P. (2013), "Critical service logic: Making sense of value creation and co-creation", Journal of the Academy of Marketing Science, Vol. 41 No. 2, pp. 133-150. https://dx.doi/org/10.1007/s11747-012-0308-3.

Kim, Y. S. et al. (2009), “A Product-Service System Representation and Its Application in a Concept Design Scenario", In: Proceeding of the 1st CIRP Industrial Product-Service System (IPS2) Conference. Cranfield University, Cranfield, pp. 32-39. https://dx.doi/org/10.4271/2009-01-0717.

Liedtka, J. and Ogilvie, T. (2011), "Designing for growth: a design thinking tool kit for managers”, Columbia University Press, USA.

Lim, C. H. et al. (2012), "PSS Board: A structured tool for product-service system process visualization", Journal of Cleaner Production. Elsevier Ltd, Vol. 37, pp. 42-53. https://dx.doi/org/10.1016/j.jclepro.2012.06.006.

Maussang, N., Zwolinski, P. and Brissaud, D. (2009), "Product-service system design methodology: from the PSS architecture design to the products specifications”, Journal of Engineering Design, Vol. 20 No. 4, pp. 349-366. https://dx.doi/org/10.1080/09544820903149313.

Morelli, N. and Tollestrup, C. (2007), "New Representation Techniques for Designing in a Systemic Perspective", In: Design Inquiries, Nordes 07 Conference. Stockholm, pp. 81-86.

Nenonen, S., Rasila, H. and Junnonen, J. M. (2008), “Customer Journey - a method to investigate user experience", W111 Research Report Usability of Workplaces. Available at: www.irbnet.de/daten/icoda/CIB8909.pdf.

Ortbal, K., Frazzette, N. and Mehta, K. (2016), "Stakeholder journey mapping: An educational tool for social entrepreneurs”, In: Procedia Engineering. Elsevier, Massachusetts, USA, pp. 249-258. https://dx.doi/org/10.1016/j.proeng.2016.08.170.

Panarotto, M. (2015), “A Model-Based Methodology for Value Assessment in Conceptual Design”, Bleking Institute of Technology. Available at: http://bth.divaportal.org/smash/record.jsf?pid=diva2\%3A866719\&dswid=_new.

Resta, B. et al. (2017), "Enhancing the Design and Management of the Product-Service System Supply Chain: An Application to the Automotive Sector”, Service Science, Vol. 9 No. 4, pp. 302-314. https://dx.doi/org/10.1287/serv.2017.0193.

Roy, R. and Cheruvu, K. S. (2009), “A competitive framework for industrial product-service systems”, International Journal of Internet Manufacturing and Services, Vol. 2 No. 1, p. 4. https://dx.doi/org/10.1504/IJIMS.2009.031337.

Rozenfeld, H., Rosa, M. and Fernandes, S. Da C. (2018), "Servitization methodology: PSS design, change management or business model innovation?”, In: Schützer, K. (ed.) Proceedings of the 23rd International Seminar on High Technology. UNIMEP, Piracicaba, pp. 91-116.

Sampson, S. E. (2012), "Visualizing Service Operations", Journal of Service Research, Vol. 15 No. 2 , pp. 182-198. https://dx.doi/org/10.1177/1094670511435541.

Shostack (1982), "How to design a service”, European Journal of Marketing, Vol. 16 No. 1, pp. 49-63.

Sperano, I. et al. (2019), "Exploring New Usages of Journey Maps: Introducing the Pedagogical and the Project Planning Journey Maps", In: Proceedings of the 20th Congress of the International Ergonomics Association (IEA 2018). Springer Nature, Switzerland, pp. 964-982. https://dx.doi/org/10.1007/978-3-319-96098-2.

Tan, A. R. (2010), "Service-oriented product development strategies”, Technical University of Denmark.

Temkin, B. D. (2010), "Mapping the customer journey", For Customer Experience Professionals, Forrester Research.

Tukker, A. (2004), "Eight types of product-service system: Eight ways for sustainability? Experiences from SUSPRONET", Business Strategy and the Environment, Vol. 13, pp. 246-260. https://dx.doi/org/10.1002/bse.414.

UNICA (2018), "Brazilian Sugarcane Sector: Recent Developments and the Path Ahead". Available at: https://www.usda.gov/oce/forum/2018/speeches/Leticia_Phillips.pdf.

Yin, R. K. (2003), “Case Study Research: Design and Methods, Clinical Research”, Sage Publications. https://dx.doi/org/10.1016/j.jada.2010.09.005.

Yip, M. H., Phaal, R. and Probert, D. R. (2015), "Characterizing product-service systems in the healthcare industry”, Technology in Society, Vol. 43, pp. 129-143.

\section{ACKNOWLEDGMENTS}

This study was supported by São Paulo Research Foundation (FAPESP) under the processes 2017/27144-3 and 2018/13024-9. The opinions, hypotheses and conclusions or recommendations expressed in this material are of responsibility of the authors and do not necessarily reflect the views of FAPESP. The authors would like to extend sincere thanks to São Paulo Research Foundation (FAPESP), Brazilian Council for Scientific and Technological Development (CNPq) and the Higher Education Personnel Improvement Coordination (CAPES) for supporting this research. 